\title{
Study of the Productive Chain of Stone Facings in Contemporary Buildings in São Paulo, Brazil
}

\author{
Eleana Patta Flain and Roberto Righi \\ Faculty of Architecture and Urbanism, Mackenzie Presbyterian University, Sao Paolo 01302-907, Brazil
}

\begin{abstract}
This article presents, based on field survey and in the consulted literature, the main procedures for fixing of claddings with plates of rocks, adopted in the city of Sao Paulo for buildings and contemporary urban works. There was an increase in the quality of these claddings in the last decades due to several factors, such as the adoption of technological innovations in the extraction process of the rocky material and in the productive chain and, also, the use of most modern procedures for projects in which are incorporated new knowledge for better use of the rocky material and reduction of waste, due to greater demands of the market in the sector of ornamental stones.
\end{abstract}

Key words: Stone cladding, dimension stone, stone veneer, architecture, rock.

\section{Introduction}

The use of claddings with dimension stones is in growth in Brazil, a situation which is reflected in bold designs that use a wide diversity of rock types with varied aesthetic results, a situation that can be seen in São Paulo and in other Brazilian cities. This is a result of the intense effort of technological updating and from professionals of engineering and architecture adopting current project criteria. This procedure has nowadays a great importance for the real estate market in the development of new products. It is important to note that the consumer needs and desires are closely linked to greater sophistication required by the end real estate product [1].

The claddings are very important in the formation of aesthetic image of the project leading to a greater commercial value, allowing you to achieve a higher profit margin. The contemporary architecture allows greater expression and use of more diversified finishing materials.

The modernism has maintained the professionals

Corresponding author: Eleana Patta Flain, professor, Ph.D. student, research fields: construction technology, quality control and stone cladding.

Roberto Righi, full professor in the graduate and post-graduate degree, Ph.D., research field: urbanism. away of this concern, which must be returned to the project, especially important in the formation of the new generation of urbanists architects [2].

In this work, relevant aspects of the process of producing the claddings with dimension stones used currently in buildings and contemporary urban works are highlighted. Following, are presented elements and parameters for projects, as well as a step-by-step guide of the main procedures for performing the cladding and, finally, some final considerations, where the importance of adopting technological solutions and future perspectives for the use of ornamental stones as cladding is highlighted.

\subsection{Description of the Problem: Current Processes for Stone Claddings of Buildings}

Despite the use of stones as cladding of buildings and urban works has intensified in the past few years in Brazil and even in other countries like Japan, China and others, the processes for fixing of the dimension stones evolved little. It can be observed in the Guangzhou Opera House (Fig. 1), by Zara Hadid, finalized in 2010, that dimension stones with low thickness were fixed utilizing metallic components, a process used in Europe since the 1940s and that, in Brazil, with a long 


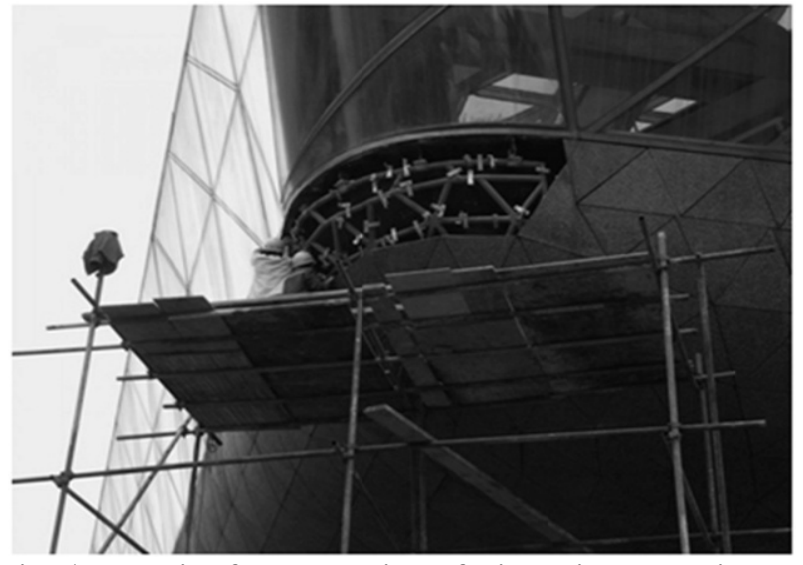

Fig. 1 Detail of the cladding of dimension stone in the façades of the Guangzhou Opera House building $\left(24,700 \mathrm{~m}^{2}\right.$ of granite) [3].

delay, only had its bigger application in the year 1983 in the construction of the building named Citycorp Center in Av. Paulista, in São Paulo (Fig. 2).

The processes currently used in Brazil for fixing the finishing with dimension stone to buildings and contemporary urban works may be two: by mechanical anchoring and by gluing (physical-chemical adhesion or mechanical adhesion). In the first one, metallic components are used; those are called metallic inserts by NBR (Brazilian Standard Registered) 15846 [4] and in the second one, conventional mortar, glues or special glues are used. When adhered through mortar, the dimension stones are directly fixed over the substratum such as in the case of floors. In facades, the Brazilian standards do not consider their use. When the dimension stones are fixed with metallic components, the stones stay away from the substratum, generally fixed in the reinforced concrete and/or steel structure. They may also be fixed to a metallic substructure (made of steel or aluminum) attached to the main one.

Besides these processes, there is also the fixing of dimension stone directly on prefabricated concrete pieces, introduced in Brazil at the beginning of the 1990s. These panels involve the entire extension of the facade, enveloping the building. The sizes are variable according to each project and to the configuration of the facades.

\section{Method and Materials}

For the research proposal, buildings and important contemporary urban works were chosen, existing in the city of São Paulo, that use stone claddings. Those buildings and works had been constructed in the last three decades. The studied buildings and works were visited for the survey data. In addition, it was consulted the bibliography about the processes used and performed the analysis of the data obtained in the works.

\section{State of the Art}

\subsection{Rationalized Process}

Rationalized processes, according to Sabattini [5], are processes in which organizational techniques used in manufacturing industries are employed in construction industries, from this resulting in no radical changes in production methods of the building. According to Taralli and Picarelli [6], these rationalized processes have incorporated principles of planning and control with the goals of: eliminate waste of workforce and materials; increase productivity; plan the production flow and centralize; and program the decisions.

The application of dimension stone components with adhesives (glue or gluing mortar) is a rationalized process and means advancement in the production technology of these cladding. It is mainly grounded on the fact that it dissociates the services of production, that is, it separates the execution of the regularization layer from that of the fixation layer. These mortars are commonly used for fixating dimension stones on floors.

One can consider the fixing of the dimension stone with the use of metallic components as a rationalized process for the following reasons: the fixation of these components happens at the moment of the placing of the stones, where the regularization layer, when it exists, is previously executed; the metallic components are manufactured outside the work site and previously 
defined in a project. Said procedures contribute to increase the process organization level.

There are several formats and types of metallic components, some being presented below. The most used types in Brazil were the pioneers, known commercially as "American system" (Fig. 2a) and "German system" (Fig. 2b). Both can be fixated to the lateral or upper and lower surfaces through holes in the plates of stone. The difference is the first which requires a tear, made with a circular saw, to accommodate a thin metallic plate, while the second requires only a hole, made with a drill, to insert a pin. In practice, due to removing less rocky material, the German method weakens less the plate and has been adopted, allowing for the use of thinner plates, even under $30 \mathrm{~mm}$.

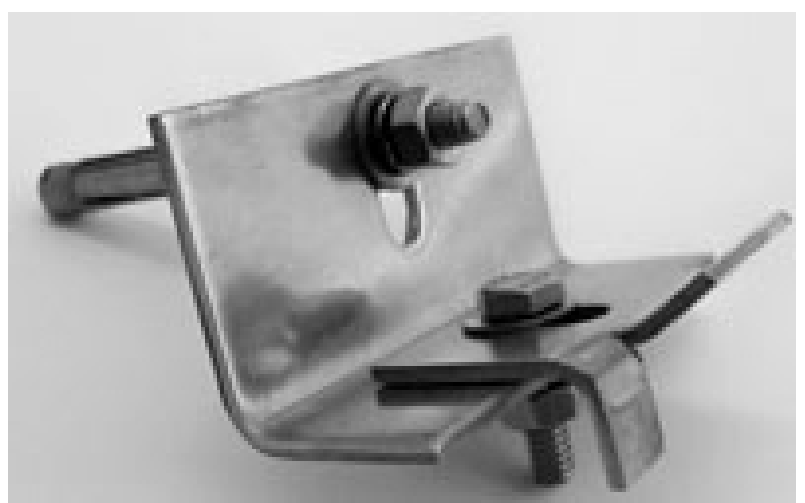

(a)
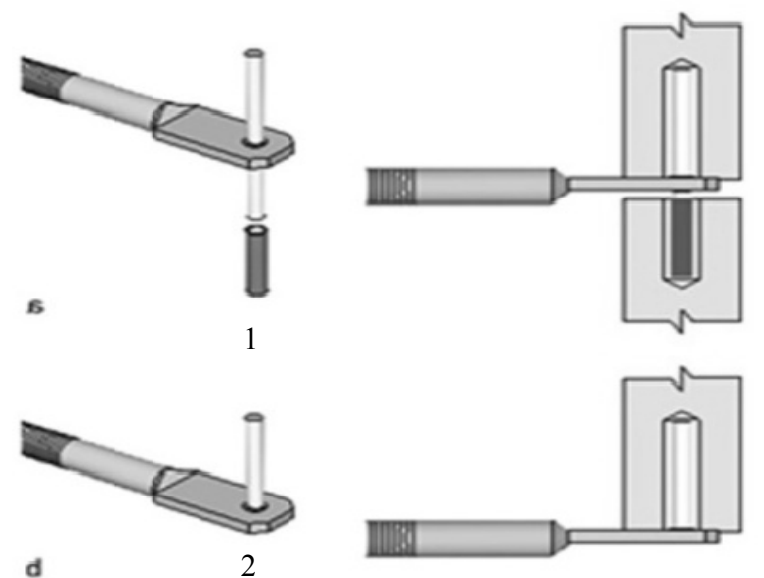

(b)

Fig. 2 Types of fixation system: (a) American system; ${ }^{1}$ (b) German system (1: loose pin and sliding glove; 2: support with the pressed half-pin) [7].

\footnotetext{
${ }^{1} \mathrm{http} / / /$ www.granprometal.com.br.
}

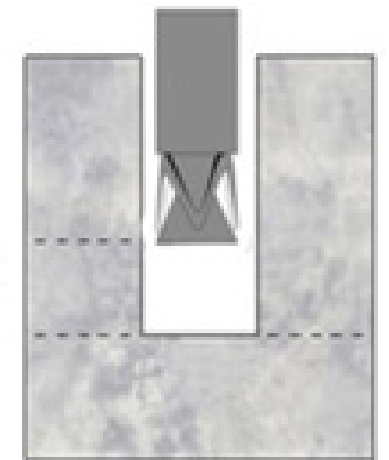

Fig. 3 Anchor with external thread or anchor with internal thread.

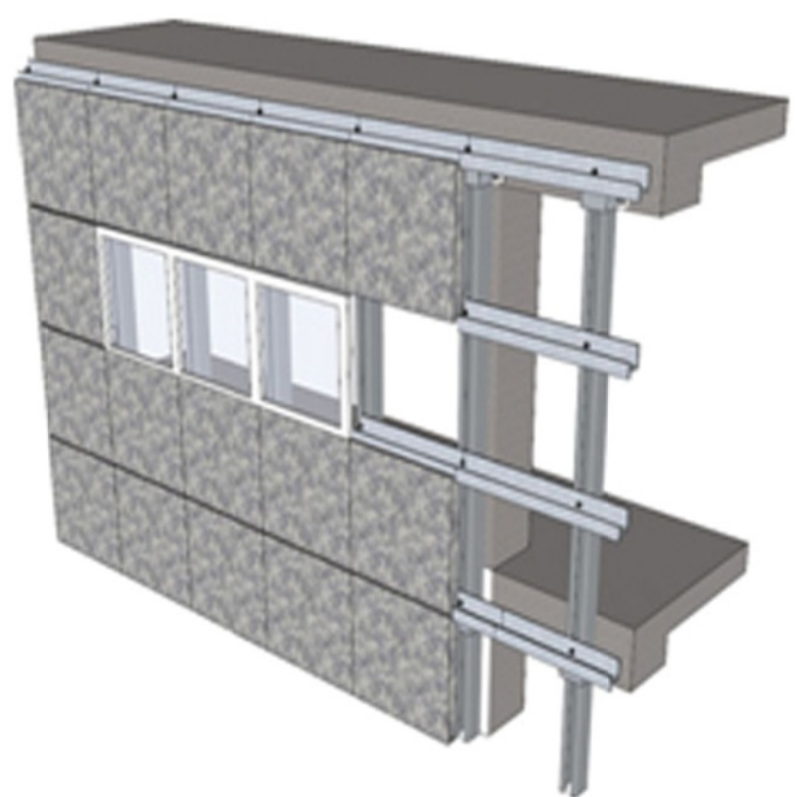

Fig. 4 Stone plates fixated on an aluminum substructure $[7,8]$.

perforated on its back (wall-backing) and, at the base of the hole, with the insert itself, there are the enlargings of the opening where it will be anchored. This system is illustrated in Fig. 3.

Fig. 4 illustrates the system for assembling stone plates on an aluminum structure (substructure), widely used in developed countries. In Brazil, it is seldom used when compared to the other fixation systems due, especially, to the high cost of structural aluminum.

\subsubsection{Traditional Process}

In Brazil, it is still the most used for placing stone plates on floors of buildings and urban works, especially in the furthest regions of large centers, where it is harder to obtain new materials and 
specialized workforce. The conventional modular cladding is the traditional method for placing claddings using conventional mortar [7].

\subsection{Elements and Parameters for the Elaboration of a Project}

\subsubsection{Project Elements}

(1) Frontal view of the surfaces to be cladded with the distribution (pagination) of the plates in an adequate scale;

(2) Constructive details of the fittings, crevasses and holes in the plates, metallic components, dilation joints, fixations to the support, among others; and the position of the fixation components, in the case of front claddings;

(3) Descriptive memorial with information about the materials and services, also presenting the maximum tolerance allowed for plumb deviations and flatness of the cladding and those required for the supports. A planning and the periodicity for performing the inspections must also be present, encompassing the following aspects:

- state of the sealings (continuity, adherence to the surfaces of the joints, cohesion and the presence of fissure);

- existence of corrosion of the metallic fixation components;

- indications of lack of adherence of the plates fixated with mortar (hollow sound when knocked);

- occasional displacement of the plates, among other relevant aspects of the cladding.

Flain and Cavani [9] recommend that, in order to reach the end stage of the project phase, the professionals (architect or designer) consider all important factors, especially regarding quality, performance and the cost of the end product. Besides this, the knowledge of the parameters that may interfere in the end result of the project is necessary. It is emphasized that, besides an adequately elaborated project, the follow-up of the execution of the services and the training of the workforce for obtaining quality end product at a lower cost is of utmost necessity [7].

3.2.2 Parameters for Project Requests

The actions to which the stone plates and their fixation components will be subjected during the works of placement and working life of the cladding are as follows, according to Flain [7]:

(1) Loads Parallel to the Plane of the Plates

The own weight of the plates and of a possible thermal insulation layer; in the case of placing of stone plates on facades, with metallic components, the own weight of the plates is relevant because it will define the vertical loads that will act upon the metallic fixation component, being a information for its dimensioning, as it is important tool for the dimensioning of prefabricated panels;

(2) Loads Perpendicular to the Plane of the Plates

- wind action. The efforts due to wind must be calculated as per NBR 6123 [10];

- accidental impacts. The stone plates, especially those located at lower levels on the facades, inner walls and floors, are more subject to accidental shocks. At great heights, the suspended work platform used may cause shocks on the plates.

(3) Requests due to the Relative Movement of the Support and of the Cladding

- deformations due to hydrothermal variations. For outer claddings, in the calculation of relative deformations between the support and the cladding layer, due to the differential thermal dilation, one must consider the difference of temperature that may occur between the surface of the cladding (taking its color into account) and the fixation layer. Certain stones absorb practically little water, while others may absorb up to $20 \%$ of its mass. The sources of humidity are: residual, by occupation of the buildings and by capillarity.

- permanent deformities due to the slow retraction and deformation of the concrete. The deformations caused by the retraction of the structure, of the masonry and the slow deformation of concrete, which may occur after the cladding be executed. It is recommended to 
wait for the highest span of time possible between the execution of the support and the subsequent layers.

\subsubsection{Choice of Materials}

The choice of the most adequate materials for cladding must be connected, especially, to its characteristics considering its use, in the case of stone: outer spaces or inner spaces, areas of walls or floors and others.

(1) Characteristics of the Rocks

In large works, before the project, it is important that it be performed a search of the deposit of the rock to check its capacity to supply taking into account the compliance with the work schedule and lithological homogeneity and aesthetic homogeneity of the rock.

In the choice of rock, the designer must consider, according to the Brazilian standards, besides the aesthetic aspects, the following elements:

- the petrographic characteristics that influence the durability of the rock;

- the physical-mechanical properties of the rock;

- the porosity and absorption of water;

- the viability of the rock being submitted to the improvement processes necessary for obtaining the desired effects (polished surface, serrated, chiseled, flamed, etc.);

- the alterations to appearance to which the plates are subjected to washing and to the action of cleaning products and others, exposed to the elements, in the case of outer claddings, to the atmospheric pollution and to the morphology of the building; to the cladding with conventional mortar.

It becomes necessary that, besides aesthetic aspects, rocks are chosen based on their technological characteristics to fill safely and reliably the architectural goals [11].

(2) Characteristics of the Metallic Components for Fixating

The metallic fixation components must be made up of inalterable metals. According to NBR 15846 [4], the main metallic alloys that can be used for the metallic fixation components are: stainless steel (Type ABNT
304 - for urban and industrial atmospheres without chlorides, and Type ABNT 316-for urban, maritime and industrial atmospheres that contain chlorides).

(2) Characteristics of the Placing Mortar

The conventional mortar to be employed in the fixation of rock plates must be the gluing mortar that must have characteristics and properties that are compatible with the rocky material used.

(3) Characteristics of the Sealants

The sealants must:

- be resistant to the atmospheric agents;

- present good adherence to the materials to which they are applied;

- be airtight and watertight and not cause spots or changes to the materials to which they are applied;

- being inert in the presence of chemical substances normally found in buildings (alkalinity of the mortars and cleaning products);

- being sufficiently elastic and keeping as such through time.

\subsection{Dimensioning of the Stone Plates}

The dimensioning of the rock plates restricts itself to the determination of their thickness as a function of their dimensions (length and width), of the mechanic characteristics of the rock, of the fixation system to be employed and of the loads at work. The determination of the thickness of the plates can also be done from tests of the set of "fixation metallic component plate", in the case of cladding for facades, and set "support system plate", for instance, in the case of high floors.

The joints that make up the cladding can be: between components, for moving or constructive and structural. The joints have roles of aesthetic finishing, air and water tightness and absorbing the deformities that may occur in the cladding.

Moving joints must be foreseen in the encounter of distinct materials and in elements that project themselves beyond the cladding plan. Structural joints, when foreseen, must be respected in position and width in the coating. 
The materials used for finishing the joints are sealants and mortars. The use of mortars for rejoining the joints between components when the coating layer is not subject to the action of high-intensity forces, such as, for instance, internal claddings.

For external claddings, sealants are recommended for rejoining the joints between components and moving joints, due, especially, to their deformability characteristics.

For the joints between plates, when fixated with metallic components, they may be rejoined with sealants or remain open at the discretion of the project. Some works, in Brazil and abroad, suppressed the use of finishing of the joints in the system with metallic fixation without prejudice to the performance of the coating.

\section{Step by Step: Relevant Aspects in the Process of Fixation of Stone Plates to Walls}

In following, we present relevant aspects of the fixation of stone plates to walls of buildings and other urban works using metallic components.

\subsection{Preparation of the Support}

It is commonly performed the waterproofing of concrete structures with two coats of bituminous paint, when the execution of claddings with rock plates is made with metal components. For the walls executed with concrete or ceramic blocks, it is recommended to perform a mortar coating and after waterproof it with bituminous paint as made with concrete structures. Note that, if the layer of mortar is not executed, the bituminous sealing only will not ensure the tightness of the walls.

\subsection{Execution of the Cladding}

Metallic components are fixated to the support through bolt tensioners, preferably stainless steel ones. The holes for fixation of the bolt tensioners are made with the aid of an impact drill with a boring beat. During the execution of the holes, one must be attentive to detect if they do not coincide with some locking hole for the casts or with a possible concreting rift, because, in these conditions, the fixation may be compromised. It is recommended that the residues that come from the drilling are removed before the placing of the bolt tensioner.

The position of the bolt tensioners must be always perpendicular to the support. For the placing of the bolts, the use of a tapping tool and, for the adjustment and verification of the tightness, the use of a torque meter. It is recommended that, when there are doubts about the loads (unfavorable conditions of the support) that will support the bolts, tests are requested to verify these loads.

Once the sustaining-type components are positioned, the stone plates are installed, with their lower tears filled with sealant. For placing the sealant in the plate tears, they must be dry. Then, the retaining-type components are installed, adjusting the position of the plate and previously filling the upper tears of the plates with sealant. In this case, the role of the sealant is to avoid the penetration of water from rain or from the cleaning of the coating into the holes and crevasses of the plates.

\subsection{Execution of the Joints}

Before the rejoining, it is recommended that any material that may harm the adherence of the sealer or its continuity is removed from within the joints, that they are duly cleaned with cloth or tarp imbibed in an isopropanol-type solvent. The application of a primer to the side faces of the joints so as to improve the adherence of the sealant is also recommended. The sealant must be applied before the full drying of the primer taking care not to stain the plates. It is recommended to put crepe tape on the face of the joints to avoid the contact of the sealant and/or primer with the surface of the plates. After the application of the sealant, clean the borders of the joints for the removal of the excesses with an isopropanol-type solvent.

In these constructive or moving joints, after cleaning, 
the joint back must be put under pressure, so that it is adequately positioned. The use of a component with enough width for penetrating the joint and that will pressure the cord to the desired depth is recommended. For a better finishing of the joint, smoothen the sealing surface.

\section{Results}

In Fig. 5, it is presented the Citycorp Center, the facades of which were coated with dimension stone of granite commercially known as "Rosa Biritiba", fixed with metallic components in the structure. This work marks the beginning, in Brazil, of the use of stone cladding on building facades through the fixation with metallic components. The detail of a fixation system with metallic components is illustrated in Fig. 6.

Fig. 7 shows the Rochaverá Corporate Tower, built in the city of São Paulo, an example of use of prefabricated panels in a contemporary building, where it was used the stone known commercially as "bege Ipanema". In this industrialized process, the dimension stones are fixed on the prefabricated concrete panels through the use of stainless steel hooks, as per the detail in Fig. 8.

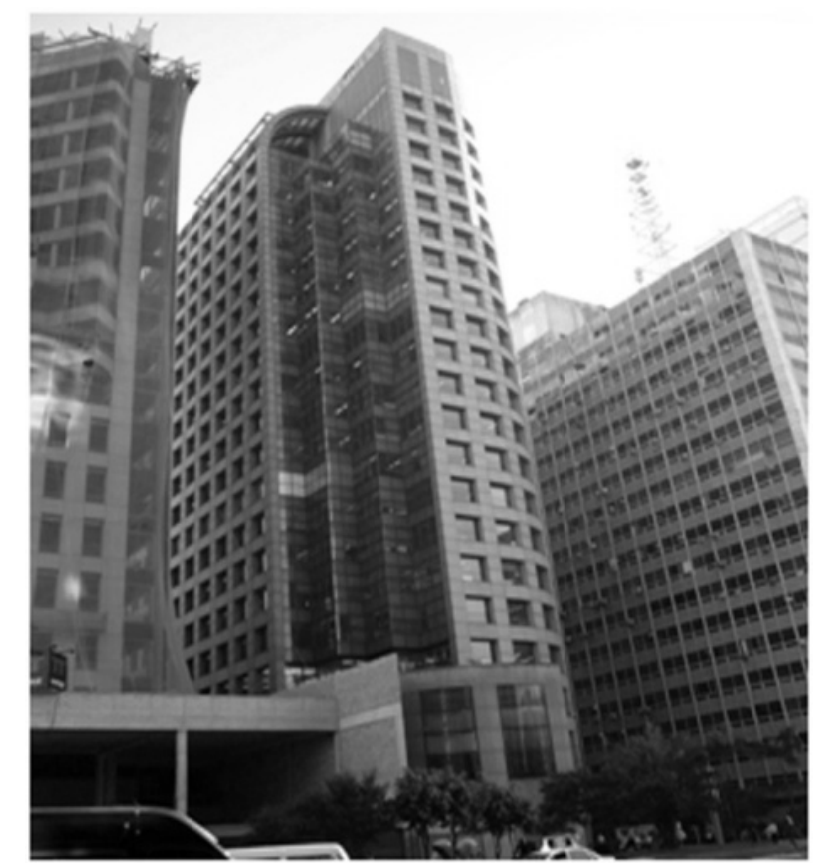

Fig. 5 Citicorp Center building located at Avenida Paulista.

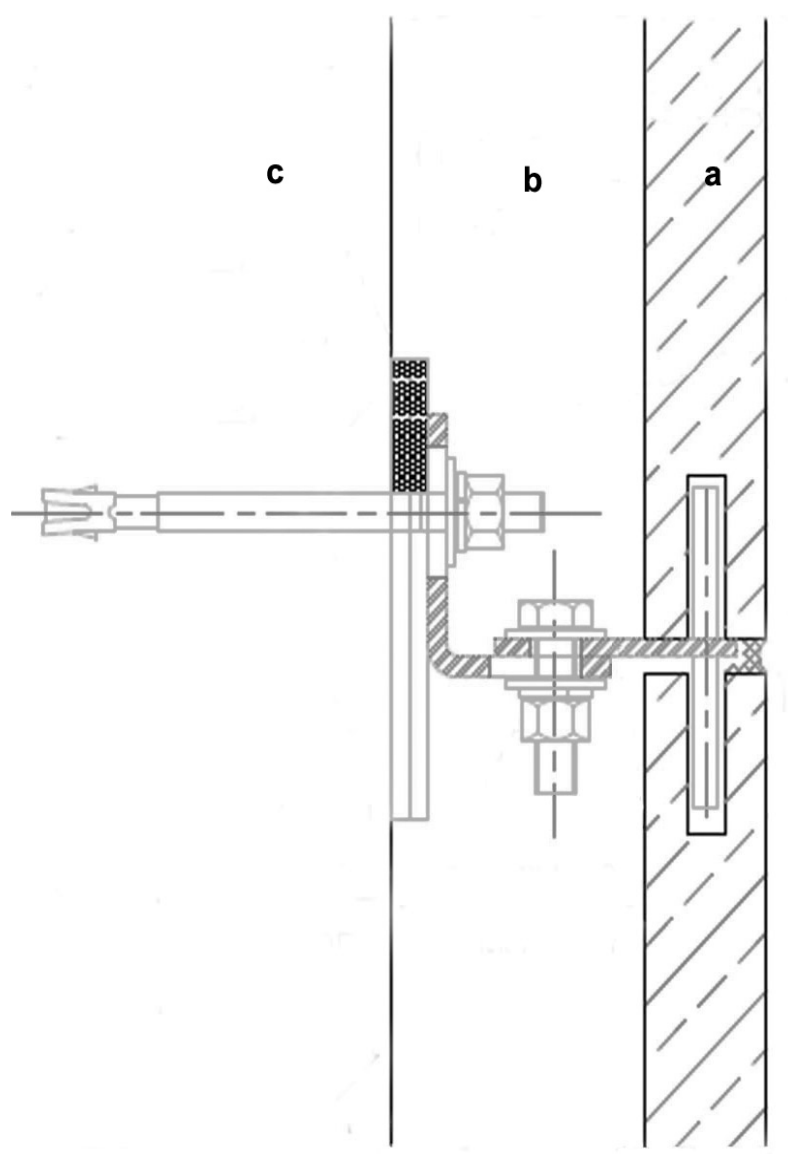

Fig. 6 Detail of dimension stone fixed with metallic components (a: dimension stone; b: empty space between the stone and the substrate; $c$ : posterior face of the insulation).

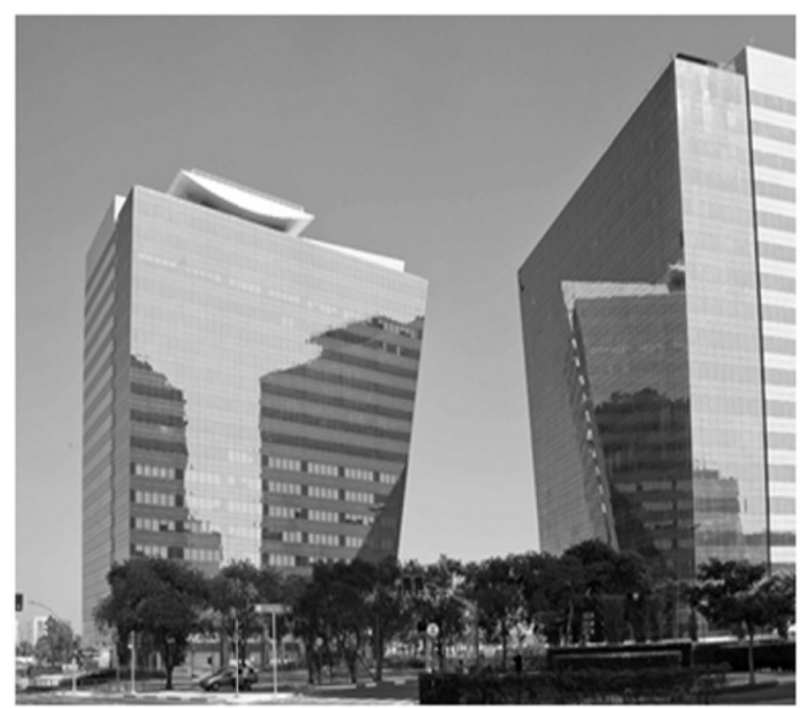

Fig. 7 The facades of the buildings of Rochaverá Corporate Towers have prefabricated elements fixated to the structure enveloping the building. ${ }^{2}$

${ }^{2}$ http://www.metodo.com.br. 


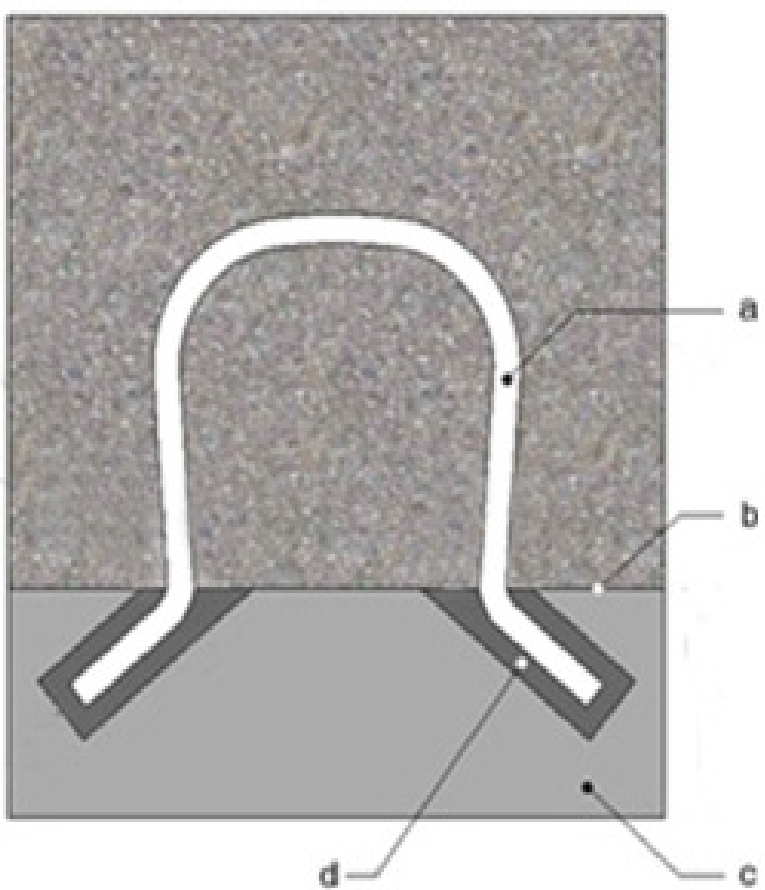

Fig. 8 Detail of a typical section of the fixation of the dimension stone to a prefabricated panel (a: stainless steel anchoring; $b$ : junction between the dimension stone and the prefabricated concrete component; c: dimension stone; $d$ : cavity filled with epoxy; e: hole depth; f: steel plate).

\section{Conclusions}

It is understood that, in order to contribute with quality, performance and productivity in the placing of stone claddings, the technological development of constructive processes used in the country, the rationalization of the processes and the adoption of technological innovations, associated to the consolidation in the work sites, become necessary.

Considering that the ornamental stone sector has been installed in the Country for a long time and the importance that stone claddings represent for civil construction, it can be stated that these claddings still have a low use compared, for instance, to the ceramic and glass ones.

So as to contribute more and more for the increase in use, for the valuation of rocks available in the Brazilian market, some perspectives are presented below that may contribute for an increase in the use of this material as cladding in buildings and urban works.
There is a need for:

- investing in higher advertising of the characteristics and properties of the rocks for claddings since there is a large variety of commercially available rocks in the Brazilian market that can be used;

- an increase in the investments in studies and research, since there are universities and research institutes that are recognized all around the country and that may provide technical and scientific support for the sector;

- the existence of highly trained companies and professionals in the sector that contribute for divulging and using rocks as cladding.

\section{References}

[1] Righi, R., Castro, L. G. R. de., Duarte, C. R., et al. 2007. A Edificação como Produto Imobiliário no Desenvolvimento da Arquitetura Contemporânea em São Paulo in O Lugar do Projeto no Ensino e na Pesquisa em Arquitetura e Urbanismo. Rio de Janeiro: UFRJ. (in Portuguese)

[2] Righi, R. 2000. “Arquitetura Moderna e Contemporânea Brasileira: Exercício Profissional e Ensino.” Dynamis 8: 60-5. (in Portuguese)

[3] Moore, M. 2011. "Guangzhou Opera House Falling Apart." The Telegraph. Accessed May 20, 2015. http://www.telegraph.co.uk/news/worldnews/asia/china/8 620759/Guangzhou-Opera-House-falling-apart.html.

[4] Associação Brasileira de Normas Técnicas. 2010. ABNT: Rochas para revestimento: Projeto, Execução e Inspeção e Revestimento de Fachadas de Edificações com Placas Fixadas por Insertos Metálicos-NBR 15846. Rio de Janeiro: ABNT. (in Portuguese)

[5] Sabattini, F. H. 1989. Desenvolvimento de Métodos, Processos e Sistemas Construtivos: Formulação e Aplicação de uma Metodologia. São Paulo: Escola Politécnica, Universidade de São Paulo. (in Portuguese)

[6] Taralli, C. H., and Picarelli, M. 1984. Mudança de Tecnologia na Habitação: Os Conjuntos Habitacionais da COHAB-SP. São Paulo, Faculdade de Arquitetura e Urbanismo de São Paulo. (in Portuguese)

[7] Flain, E. P. 1995. Tecnologia de Produção de Revestimentos de Fachadas de Edificios com Placas Pétreas. São Paulo: Escola Politécnica, Universidade de São Paulo. (in Portuguese)

[8] Camposinho, R. de S. 2014. Stone Cladding Engineering. New York, London: Springer.

[9] Flain, E. P., and Cavani, G. de R. 1994. "Revestimentos Verticais com Placas de Rocha." Téchne 2: 59-63. (in 
Portuguese)

[10] Associação Brasileira de Normas Técnicas. 2013. ABNT: Forças Devidas ao Vento em Edificações-NBR 6123: 1988. Versão corrigida. São Paulo: ABNT. (in Portuguese)
[11] Frazão, E. B., and Caruso, L. G. 1989. "Manutenção em Revestimentos de Pedra in Anais Simpósio.” Nacional de Tecnologia da Construção Civil 10: 89-99. (in Portuguese). 